\title{
Assessing sensitivity to change: choosing the appropriate change coefficient
}

\author{
Paul W Stratford ${ }^{* 1,2}$ and Daniel L Riddle 3
}

\begin{abstract}
Address: ${ }^{1}$ School of Rehabilitation Science, McMaster University, Hamilton ON, L8S 1C7 Canada, ${ }^{2}$ Department of Clinical Epidemiology and Biostatistics, McMaster University, Institute for Applied Health Science, 1400 Main Street West (4th floor), Hamilton ON, L8S 1C7, Canada and ${ }^{3}$ Department of Physical Therapy, Medical College of Virginia Campus, Virginia Commonwealth University, 1200 East Broad Street, Richmond, VA 23298-0224, USA
\end{abstract}

Email: Paul W Stratford* - stratfor@mcmaster.ca; Daniel L Riddle - dlriddle@vcu.edu

* Corresponding author

Published: 05 April 2005

Health and Quality of Life Outcomes 2005, 3:23 doi:10.1 186/1477-7525-3-23

This article is available from: http://www.hqlo.com/content/3/l/23

(c) 2005 Stratford and Riddle; licensee BioMed Central Ltd

This is an Open Access article distributed under the terms of the Creative Commons Attribution License (http://creativecommons.org/licenses/by/2.0), which permits unrestricted use, distribution, and reproduction in any medium, provided the original work is properly cited.
Received: 02 March 2005

Accepted: 05 April 2005

\begin{abstract}
The past 20-years have seen the development and evaluation of many health status measures. Unlike the high standards demanded of those who conduct and report clinical intervention trials, the methodological rigor for studies examining the sensitivity to change of health status measures are less demanding. It is likely that the absence of a criterion standard for change in health status contributes to this shortcoming. To increase confidence in the results of these types of studies investigators have often calculated multiple change coefficients for the same patient sample.

The purpose of this report is to identify the conflict that arises when multiple change coefficients are applied to the same patient sample.

Three families of change coefficients based on different assumptions concerning the sample composition are identified: (I) the sample is homogeneous with respect to change; (2) subgroups of patients who truly change by different amounts exist; (3) individual patients, many of whom truly change by different amounts exist. We present several analyses which illustrate a major conceptual conflict: the signal (a measure's true ability to detect change) for some of these coefficients appears in the noise term (measurement error) of the others.

We speculate that this dilemma occurs as a result of insufficient preparatory work such as pilot studies to establish the likely change characteristic of the patient population of interest. Uncertainty in the choice of change coefficient could be overcome by conducting pilot studies to ascertain the likely change characteristic of the population of interest. Once the population's change characteristic is identified, the choice of change coefficient should be clear.
\end{abstract}

\section{Review}

The past two decades have seen considerable interest in the development and evaluation of health status outcome measures [1-14]. Although the assessment of reliability and cross-sectional validity is straightforward, the same cannot be said about the evaluation of a measure's ability to detect change. Investigators have often expressed uncertainty in the choice of study design and analysis, and statements such as the following are common: "Because there is not yet agreement on the optimal design and analysis strategies for a responsiveness study, the authors evaluated the responsiveness of the FRI and RM-18 using two 
methods" [10]; "A variety of statistics have been used to assess responsiveness and no single one is superior" [2]; and "The purpose of this study was to determine if different indices of responsiveness provided similar rank orderings of scales in terms of responsiveness" [5]. It is likely that the absence of a gold standard for change in health status plays a prominent role in stimulating uncertainty in the choice of analysis. The solution to the expressed conundrum has often been the application of a "shotgun analysis" where multiple change coefficients are applied to a common dataset $[2,4,5,9-14]$. In this paper we provide a brief review of prominent study designs and change coefficients, and illustrate the conflict in applying change coefficients from different "families of analytic methods" to the same data.

\section{Methodological shortcomings}

The methodological sophistication and standards for reporting clinical intervention trials stand in sharp contrast to those evident for longitudinal validity studies of sensitivity to change. Agencies funding clinical trials demand a clearly stated research question, evidence often in the form of a pilot study - supporting the sample size, and a statement justifying the analysis. Journal editors require equal clarity and rigor when manuscripts pertaining to clinical trials are considered for publication. All too frequently reports of sensitivity to change of various health status measures appear to be "studies of opportunity," rather than carefully planned investigations. Notably absent from many studies are a clear statement of purpose, elaboration of design details including the expected extent to which the sample's true change is likely to be homogeneous or heterogeneous (we will subsequent refer to this as the sample's change characteristic), justification of sample size, and a commitment to the most appropriate analysis $[2,5,6,9,11,14,15]$. The importance of specifying the change characteristic of the sample is that it dictates the choice of change coefficient, or at least the family from which the change coefficient will be selected.

\section{Study designs and sample change characteristics}

Previous monographs have provided comprehensive reviews of popular designs for sensitivity to change studies [16-18] and it is not our intent to repeat these discussions. However, to set the stage we identify three popular designs and their corresponding samples' change characteristics: (1) patients who are expected to truly change by approximately the same amount are assessed at two points in time [1]; (2) two or more identifiable subgroups of patients who are expected to change by different amounts are assessed at two points in time [19]; and (3) patients, many of whom, are expected to truly change by different amounts are assessed at two points in time [20]. To distinguish between Designs 1 and 3 we will refer to
Design 1 as being homogeneous and Design 3 as being heterogeneous with respect to change. Design 2 shares the characteristics of Designs 1 and 3. Consistent with Design 1 is the assumption that patients within a subgroup truly change by approximately the same amount and the extent to which differences occur is attributed to measurement error. Like Design 3, the ability of a measure to detect true change is reflected by the extent to which the measure is capable of differentiating the amount of change between units that truly change by different amounts. The units are groups of patients for Design 2 and individual patients for Design 3.

Although the three study designs are conceptually simple, ascertaining a sample's change characteristic is more demanding. Perhaps the most popular method, particularly for Designs 2 and 3, has been the retrospective global rating of change $[4,5,13,14,21]$. Here, at the follow-up assessment patients provide their impression of global change in addition to completing the measure of interest. This single item global rating of change is then used as the standard for assessing the measure's ability to detect change. Norman and colleagues [22] have challenged this approach on three counts: (1) the notion that the measurement properties of the single item global rating are superior to the multi-item measure under investigation; (2) judgments of change are psychologically difficult and therefore suspect; and (3) correlated measurement error between the global rating and the measure under investigation inflates the true association between the two ratings. With respect to the last point, Norman et al [22], showed that the retrospective global rating of change can result in declaring a measure responsive in a sample of stable patients.

An alternative to the retrospective rating is the prognostic rating of change $[19,23-25]$. This approach is not subject to errors of recall or correlated error; however, it is dependent on the ability of the rater to accurately estimate the extent of change that might occur. As the name suggests, the essential feature of the prognostic rating method is an a priori declaration of the sample's change characteristic. Sensitivity to change studies have applied three designs using prognostic ratings of change: (1) randomized trials where interventions of known effectiveness are compared to placebo or weaker interventions [19]; (2) cohort studies where a known prognostic variable is used to classify patients into groups that are expected to change by different amounts [25]; and (3) clinicians assign expected change scores to patients at their initial visit $[23,24]$. Meenan et al $[19]$, in a three group (placebo, oral gold, injectable gold) randomized controlled trial, investigated the sensitivity to change of the Arthritis Impact Measurement Scales and several other clinical measures. Consistent with a priori hypotheses, the measures 
demonstrated a gradient in treatment effects with the injectable gold group demonstrating the greatest change and the placebo group showing least change. Stratford and Binkley [25] applied a cohort design where the natural history of patients with low-back pain was used to established two groups of patients with different change characteristics. Specifically, these investigators theorized that patients with low-back pain of less than 2-weeks duration would change more over the subsequent 2-week interval than would patients who presented with lowback pain of 2 or more weeks duration. Westaway et al [23] investigated the sensitivity to change of the Neck Disability Index (NDI) [26] and Patient Specific Functional Scale (PSFS) [27]. These investigators theorized that seasoned clinicians' would be able to distinguish among patients who would change by different amounts over an interval of several weeks. At the initial assessment clinicians rated patients' prognoses on a 5-point scale. Prognostic ratings were based on clinical judgment alone. The results demonstrated significant correlations between the prognostic rating of change and the measures' change scores.

\section{Study designs and their respective families of analytic methods}

Sensitivity to change studies are rich with descriptions of change coefficients $[2,5,6,9-12,15]$ which we place in the following three groups or families according to study design: Design 1, coefficients based on homogeneity of patients change characteristics; (2) Design 2, between group contrast coefficients; (3) Design 3, correlation coefficients.

\section{Homogeneous patient change}

This design and analysis is based on the premise that the sample consists of patients who are expected to change by approximately the same amount over the study period. Of interest is not what accounts for the change - it could be the natural history or the application of an effective intervention - but rather that the amount of change is expected to be reasonably homogeneous among patients. The ability of a measure to assess change is quantified by dividing the mean change (signal) by the variation in change or sample characteristics at baseline (noise). The standardized response mean (SRM = mean change/standard deviation of change) [1] is a frequently reported change coefficient associated with this design. Statistical tests include the paired t-test and repeated measures ANOVA with one within patient factor (occasion at 2 levels: baseline and follow-up) and no between patient factor. Of the three designs, this one is considered to be the weakest because it does not challenge a measure's ability to discriminate among different amounts of change [16,17].

\section{Heterogeneous patient composition: between group contrast}

This design is based on the premise that identifiable subgroups of patients who change by different amounts exist. Change coefficients include area under receiver operating characteristic (ROC) curves [18] and Norman's S repeat $_{\text {[28]. }}$ Statistical analyses for this design include the z-statistic for the area under a ROC curve [16], t-test for independent sample means of change scores, and repeated measures analysis of variance (ANOVA) with one within patient factor (occasion at 2 levels) and one grouping factor (amount of change at 2 or more levels: small change, large change) [28].

\section{Heterogeneous patient composition: among patient contrast}

Like the first design, this one investigates a single group of patients. However, rather than the patients being reasonably homogeneous with respect to change, the patients are expected to truly change by different amounts. Moreover, an essential aspect of this design is that an external standard is applied, the change scores of which are compared to the change scores of the measure of interest. A measure's ability to detect change is based on a correlation analysis $[5,16,17]$.

\section{Problem clarification}

Investigators have often applied analyses and change coefficients from the three families of tests to the same patient sample $[4,6,9,11]$, apparently without realizing that the coefficients are based on different, and at times conflicting assumptions concerning the sample's change characteristic. For example, Kopec et al [4] reported a study that was conceived to "determine whether the Quebec scale (a functional status measure for patients with low-back pain) is a reliable, valid, and responsive measure of disability, in back pain, and to compare it with other disability scales." The sample was diverse in that it included patients from physical therapy clinics, physiatry centers, rheumatology clinics, family practice groups, and pain clinics. Statistical tests included the paired t-test, repeated measures ANOVA with one grouping factor (amount of change), and a correlation of the Quebec's change scores with those of a retrospective global rating of change. Change coefficients included the SRM [1], Norman's $S_{\text {repeat }}[28]$, and an unnamed correlation coefficient. The three analyses were applied to the same group of patients. To underscore the theoretical conflict in applying these coefficients to the same patient sample we will link the coefficients reported by Kopec et al [4] through repeated measures and regression ANOVA tables.

\section{Illustrative comparison of change coefficients}

To facilitate discussion, we will make reference to the dataset displayed in Table 1 . These data represent the 
Table I: Summary of synthetic data

\begin{tabular}{|c|c|c|c|c|c|}
\hline Patient ID & Initial Assessment & Follow-up Assessment & Change Initial-follow-up & Global Rating & Global Rating Dichotomized \\
\hline I & 16 & 14 & 2 & 3 & 0 \\
\hline 2 & 14 & 14 & 0 & 1 & 0 \\
\hline 3 & 13 & 5 & 8 & 6 & 1 \\
\hline 4 & 19 & 10 & 9 & 5 & 1 \\
\hline 5 & 14 & 8 & 6 & 6 & 1 \\
\hline 6 & 3 & 4 & -1 & 2 & 0 \\
\hline 7 & 18 & 12 & 6 & 3 & 0 \\
\hline 8 & 8 & 6 & 2 & 5 & I \\
\hline 9 & 10 & 5 & 5 & 7 & 1 \\
\hline 10 & 12 & 9 & 3 & 6 & 1 \\
\hline 11 & 14 & 10 & 4 & 5 & 1 \\
\hline 12 & 9 & 9 & 0 & 3 & 0 \\
\hline 13 & 10 & 8 & 2 & 6 & 1 \\
\hline 14 & 14 & 10 & 4 & 4 & 0 \\
\hline 15 & 17 & 16 & I & I & 0 \\
\hline 16 & 9 & 6 & 3 & 2 & 0 \\
\hline 17 & 9 & 8 & 1 & 1 & 0 \\
\hline 18 & 13 & 7 & 6 & 6 & 1 \\
\hline 19 & 8 & 4 & 4 & 4 & 0 \\
\hline 20 & 13 & 8 & 5 & 7 & 1 \\
\hline Mean & 12.15 & 8.65 & 3.50 & 4.15 & \\
\hline St. dev. & 3.92 & 3.38 & 2.71 & 2.03 & \\
\hline
\end{tabular}

Table 2: Repeated measures ANOVA with one within patient factor and no grouping factor

\begin{tabular}{lcccc}
\hline Source & DF & SS & MS & F, (p) \\
\hline Between Patients & 19 & 439.60 & 23.14 & \\
Within Patients & $\mathbf{2 0}$ & 192.00 & 122.50 & $33.49,(<0.001)$ \\
$\quad$ Occasion & 1 & 122.50 & 3.66 & \\
$\quad$ Error & 19 & 69.50 & & \\
\hline
\end{tabular}

results from a hypothetical study where a health status measure was administered to 20 patients at their baseline assessment and at follow-up 2-months later. The investigator believed that patients would improve over this interval. Also, at the follow-up visit patients provided a global rating of change on a 15-point scale (-7 to 7) [21]. Furthermore, the investigator dichotomized the patients' global ratings using a cut-point of 5 on the global rating. The investigator did not declare detailed a priori assumptions concerning the extent to which patients were expected to change by different amounts. Three analyses are presented: (1) a repeated measures ANOVA with no grouping factor and 1-within patient factor; (2) a repeated measures ANOVA with 1-grouping factor and 1-within patient factor; and (3) a correlation of the measure's change scores with those of the retrospective global rating of change. Although our illustration represents a hypothetical study, the design and analyses are consistent with the approach of Kopec et al [4] and many other studies reported in the literature $[6,9,12]$.

\section{Homogeneous patient change analysis}

The first analysis presented is a repeated measures ANOVA with no grouping factor and 1-within patient factor, occasion, at 2-levels (baseline and follow-up) [29]. The results from this analysis are shown in Table 2. The statistical analysis is equivalent to a paired t-test and the F-value of 33.49 is equal to the square of the paired $t$-value. The SRM [1] is typically defined as: 
Table 3: Repeated measures ANOVA with one within patient factor and one grouping factor

\begin{tabular}{|c|c|c|c|c|c|}
\hline Source & DF & SS & MS & $F,(p)$ & Variance \\
\hline Between Patients & 19 & 439.60 & & & \\
\hline Group & I & 3.60 & 3.60 & & \\
\hline Error & 18 & 436.00 & 24.22 & & \\
\hline Within Patients & 20 & 192.00 & & & \\
\hline Occasion & I & 122.50 & 122.50 & $46.92,(<0.001)$ & \\
\hline $\begin{array}{l}\text { Group by } \\
\text { occasion }\end{array}$ & 1 & 22.50 & 22.50 & $8.62,(0.009)$ & 1.99 \\
\hline Error & 18 & 47.00 & 2.61 & & 2.61 \\
\hline
\end{tabular}

Table 4: Regression analysis with group as a dummy variable

\begin{tabular}{lcrrrr}
\hline Source & DF & SS & MS & F, (p) & Correlation \\
\hline Regression & 1 & 45.00 & 45.00 & $8.62,(0.009)$ & $r=0.57$ \\
Residual & 18 & 122.80 & 6.82 & & \\
\hline
\end{tabular}

$$
\begin{aligned}
& \text { SRM }=\frac{\text { mean change }(\overline{\mathrm{d}})}{\text { standard deviation change }\left(\mathrm{s}_{\mathrm{d}}\right)} \\
& \mathrm{SRM}=\frac{3.50}{2.71} \\
& \mathrm{SRM}=1.29
\end{aligned}
$$

However, it can also be calculated from the repeated measures ANOVA shown in Table 2:

$$
\begin{aligned}
& \mathrm{SRM}=\frac{\sqrt{\frac{2 \mathrm{MSO}}{\mathrm{n}}}}{\sqrt{2 \mathrm{MSE}}} \\
& \operatorname{SRM}=\frac{\sqrt{\frac{2(122.50)}{20}}}{\sqrt{2(3.66)}} \\
& \mathrm{SRM}=\frac{3.50}{2.71} \\
& \mathrm{SRM}=1.29
\end{aligned}
$$

where MSO is the mean square occasions, MSE is the mean square error, and $\mathrm{n}$ is the number of patients.
Heterogeneous patient composition: between group analysis

This analysis is based on a repeated measures ANOVA with 1-between patient grouping factor at 2-levels (amount of change: a small amount or a large amount according to the dichotomized retrospective global rating of change) and the same within patient grouping factor as in the previous analysis [29]. The results are reported in Table 3. The group-by-occasion interaction term represents the extent to which the two groups changed by different amounts. The F-value for this term, $\mathrm{F}_{1,18}=8.62$, is the square of the t-value that would have been obtained had a t-test for independent sample means based on change scores been applied. Norman's $S_{\text {repeat }}[28]$ is calculated from the following information provided in Table 3:

Norman's $\mathrm{S}_{\text {repeat }}=\frac{\text { group by time variance }}{\text { group by time variance }+ \text { error variance }}$

Norman's $S_{\text {repeat }}=\frac{1.99}{1.99+2.61}$

Norman's $\mathrm{S}_{\text {repeat }}=0.43$

\section{Heterogeneous patient composition: among patient analysis}

This analysis represents a correlation of change scores with patients' retrospective global ratings of change. To show the location of the sources of variation, we generated the correlation coefficient from a regression analysis 
Table 5: Regression analysis with raw global rating change scores

\begin{tabular}{lcrrrr}
\hline Source & DF & SS & MS & F, (p) & Correlation \\
\hline Regression & 1 & 56.30 & 56.30 & $12.25,(0.003)$ & $r=0.64$ \\
Residual & 18 & 139.00 & 4.60 & & \\
\hline
\end{tabular}

[30]. Also, we provide an intermediate analysis which replicates the previous identifiable subgroup analysis. Here, "group" was coded as a dummy variable ( 0 or 1 ): it is the dichotomized rating of change shown in Table 1 . Notice that the F-value in Table 4 is identical to that for the group-by-occasion interaction term reported in Table 3. Table 5 presents the results from the correlation of change scores with the raw retrospective global ratings of change.

\section{Source of conflict among analyses}

An examination of the sum of squares terms (SS) in the ANOVA tables exposes the deficiency in applying these tests to the same dataset. Notice that when a repeated measures ANOVA with no grouping factor is applied, its SS error term contains both the group-by-occasion interaction term and the residual error from the repeated measures ANOVA with a grouping factor. Thus, to the extent that identifiable subgroups of patients exist, their presence drives down the magnitude of the SRM: the signal has become noise. The regression analyses reveal that this phenomenon extends to situations where patients truly differ in their change scores. Moreover, a comparison of the two regression analyses and correlation coefficients demonstrates that to the extent individual differences in change scores truly exist among patients, a between group analysis will under-estimate the ability of a measure to detect change.

\section{Reasons for "Agreement" among coefficients}

A natural question is if the signal for the between group and among patient change scores is contained in the noise portion of the SRM, how is it possible to obtain a change coefficient that differs from zero for this analysis? There are at least three answers.

First, the reported coefficients may not truly differ from zero. This statement is based on the observation that change coefficients are often presented as point estimates $[2,4,5]$. Without knowledge of a confidence interval or hypothesis test, one cannot ascertain the chance that a reported point estimate truly differs from zero. As a matter of interest, the 95\% confidence interval for the reported SRM of 1.29 in our example is 0.91 to 1.92 , confirming that it is highly likely that it differs from zero.
The second explanation considers a situation similar to that of our data where the SRM is greater than zero. Although self-evident, it is important to acknowledge that investigators interested in evaluating a measure's ability to detect change select patients who, in most instances, are expected to truly improve. Accordingly, the mean change for the group will be greater than zero even when some patients remain stable or get worse. When the mean change is greater than zero, the SRM will be greater than zero, even when subgroups or individual patients truly change by different amounts.

The third explanation addresses the situation where apparent patient differences in change scores, as represented by a correlation with another measure, are observed in a sample that is truly homogeneous with respect to change. In this case the design premise applied most frequently by investigators is that change scores on the measure under investigation will correlate with patients' retrospective global ratings of change. To the extent that in clinical practice clinicians ask patients about their perceptions of change, this methodology seems reasonable. However, the major limitation associated with this approach is that it spuriously inflates the observed correlation coefficient. To understand the mechanism of this apparent association, a brief review of the relationship and assumptions of observed, true, and error scores is necessary [31]. In this example, the observed scores are those reported by patients on the measure under investigation and the retrospective global rating of change. True scores are unknown values that represent the scores that would be obtained in the absence of measurement error. Error scores are the differences between observed scores and true scores. The framework for comparing the change scores of a measure to the global rating of change is that of parallel assessments of the same attribute. A fundamental assumption is that the measure's error scores and the global rating's error scores are uncorrelated [31]. However, it is extremely unlikely that the error scores are independent when a patient provides both the measure's change score and that of the global rating [22]. The consequence is that the observed correlation will be greater than zero even when the correlation between the true scores is zero. 


\section{Conclusion}

The absence of a gold standard combined with multiple change coefficients has created uncertainty for those who investigate the sensitivity to change of health status measures. In an attempt to increase confidence in a measure's ability to detect change investigators have often reported multiple change coefficients derived from the same patient sample, the belief being that uniform findings among coefficients adds to the confidence in the results. We contend that this approach is inconsistent with theory: the signal for some coefficients is included in the noise of others. We suggest that rather than calculating multiple change coefficients, a more theoretically sound approach is to devote more preparatory work to determine the likely change characteristics of the patients of interest. Once the sample's change characteristic is established, the choice of change coefficient should be clear. Moreover, when the opportunity presents, investigators are encouraged to select the more rigorous designs which not only allow the assessment of change, but also challenge a measure's ability to differentiate among patients or groups of patients who change by different amounts.

\section{Conflict of interest}

The author(s) declare that they have no competing interests.

\section{Authors' contributions}

Both authors contributed to the conceptualization and writing of this manuscript.

\section{References}

I. Liang MH, Fossel AH, Larson MG: Comparisons of five health status instruments for orthopaedic evaluation. Med Care 1990, 28:632-642.

2. Stucki G, Liang $M H$, Fossel $A H$, Katz JN: Relative responsiveness of condition-specific and generic health status measures in degenerative lumbar spinal stenosis. J Clin Epidemiol 1995, 48: $1369-1378$.

3. Deyo RA, Andersson G, Bombardier C, Cherkin DC, Keller RB, Lee CK, Liang MH, Lipscomb B, Shekelle P, Spratt KF, et al: Outcome measures for studying patients with low back pain. Spine 1994 , | 9 ( 18 Suppl):2032S-2036S.

4. Kopec JA, Esdaile JM, Abrahamowicz M, Abenhaim L, Wood-Dauphinee S, Lamping DL, Williams Jl: The Quebec Back Pain Disability Scale. Measurement properties. Spine 1995, 20(3):34I-352.

5. Wright JG, Young NL: A comparison of different indices of responsiveness. J Clin Epidemiol 1997, 50(3):239-246.

6. Poiraudeau S, Chevalier X, Conrozier T, Flippo RM, Liote F, Noel E, Lefevre-Colau MM, Fermanian J, Revel M, Rhumato R: Reliability, validity, and sensitivity to change of the Cochin hand functional disability scale in hand osteoarthritis. Osteoarthritis Cartilage 200I, 9(6):570-577.

7. Grotle M, Brox JI, Vollestad NK: Concurrent comparison of responsiveness in pain and functional status measurements used for patients with low back pain. Spine 2004, 29:E492-E50I.

8. Pengel LHM: Responsiveness of pain, disability, and physical impairment outcomes in patients with low back pain. Spine 2004, 29:879-883.

9. Willis C, Niere KR, Hoving JL, Green S, Leary EFO, Buchbinder R: Reproducibility and responsiveness of the Whiplash Disability Questionnaire. Pain 2004, I 1 0:681-688.
10. Chansirinukor W, Maher CG, Latimer J, Hush J: Comparison of the Functional Rating Index and the 18-item Roland-Morris disability questionnaire: Responsiveness and reliability. Spine 2004, 30: |4I-I45.

II. Lefevre-Colau MM, Poiraudeau S, Oberlin C, Demaille S, Fermanian J, Rannou F, Revel M: Reliability, validity, and responsiveness of the modified Kapandji index for assessment of functional mobility of the rheumatoid hand. Arch Phys Med Rehabil 2003, 84(7): $1032-1038$

12. Tidermark J, Bergstrom G, Svensson O, Tornkvist H, Ponzer S: Responsiveness of the EuroQol (EQ 5-D) and the SF-36 in elderly patients with displaced femoral neck fractures. Qual Life Res 2003, 12(8): 1069-1079.

13. Badia X, Diez-Perez A, Lahoz R, Lizan L, Nogues X, lborra J: The ECOS- 16 questionnaire for the evaluation of health related quality of life in post-menopausal women with osteoporosis. Health Qual Life Outcomes 2004, 2(I):4I.

14. Stratford PW, Binkley JM, Solomon P, Gill C, Finch E: Assessing change over time in patients with low back pain. Phys Ther 1994, 74:528-533.

15. Colle F, Poiraudeau S, Revel M: [Critical analysis of a systematic review of the literature and a meta-analysis on exercise therapy and chronic low back pain]. Ann Readapt Med Phys 200I, 44(4):22I-233.

16. Stratford PW, Binkley JM, Riddle DL: Health status measures: Strategies and analytic methods for assessing change scores. Phys Ther 1996, 76: I 109-II 23.

17. Husted JA, Cook DJ, Farewell VT, Gladman DD: Methods for assessing responsiveness: a critical review and recommendations. J Clin Epidemiol 2000, 53:459-468.

18. Streiner DL, Norman GR: Health Measurement Scales: A Practical Guide to Their Development and Use. 3rd edition. New York, Oxford University Press; 2003.

19. Meenan RF, Anderson J], Kazis LE, Egger MJ, Altz-Smith M, Samuelson COJ, Willkens RF, Solsky MA, Hayes SP, Blocka KL: Outcome assessment in clinical trials. Evidence for the sensitivity of health status measures. Arthritis Rheum 1984, 27:1344-1352.

20. Lowe A, Wessel J, Battie MC: Test-retest reliability, construct validity, and responsiveness of a functional pain scale for tennis elbow. Physiother Can 2003, 55: I | 4-I 22.

21. Jaeschke R, Singer J, Guyatt GH: Measurement of health status: Ascertaining the minimal clinically important difference. Controlled Clin Trials 1989, 10:407-4I5.

22. Norman GR, Stratford P, Regehr G: Methodological problems in the retrospective computation of responsiveness to change: the lesson of Cronbach. J Clin Epidemiol 1997, 50:869-879.

23. Westaway MD, Stratford PW, Binkley JM: The patient-specific functional scale: validation of its use in persons with neck dysfunction. J Orthop Sports Phys Ther 1998, 27(5):331-338.

24. Binkley JM, Stratford PW, Lott SA, Riddle DL: The Lower Extremity Functional Scale (LEFS): Scale development, measurement, properties, and clinical application. The North American Orthopaedic Rehabilitation Research Network. Phys Ther 1999, 79:37I-383.

25. Stratford PW, Binkley JM: A comparison study of the back pain functional scale and Roland Morris Questionnaire. North American Orthopaedic Rehabilitation Research Network. J Rheumatol 2000, 27(8): 1928-1936.

26. Vernon H, Mior S: The Neck Disability Index: a study of reliability and validity. J Manipulative Physiol Ther 199I, I4(7):409-4I5.

27. Stratford PW, Gill C, Westaway M, Binkley J: Assessing disability and change on individual patients: A report of a patient specific measure. Physiother Can 1995, 47:258-263.

28. Norman GR: Issues in the of change scores in randomized trials. J clin Epidemiol 1989, 42:1097-I I05.

29. Winer BJ: Statistical Principles in Experimental Design. 2nd edition. Toronto , McGraw-Hill; 1962

30. Kleinbaum DG, Kupper LL, Muller KE: Applied Regression Analysis and Other Multivariable Methods. 2nd edition. Boston PWS-Kent; 1987.

3I. Nunnally JC: Psychometric Theory. Toronto, McGraw-Hill; 1978. 